\title{
Simplified Design Procedure for Reinforced Concrete Columns Based on Equivalent Column Concept
}

\author{
Hamdy M. Afefy ${ }^{1), *}$, and El-Tony M. El-Tony ${ }^{2)}$ \\ (Received December 11, 2015, Accepted February 13, 2016, Published online March 11, 2016)
}

\begin{abstract}
Axially loaded reinforced concrete columns are hardly exist in practice due to the development of some bending moments. These moments could be produced by gravity loads or the lateral loads. First, the current paper presents a detailed analysis on the overall structural behavior of 15 eccentrically loaded columns as well as one concentrically loaded control one. Columns bent in either single curvature or double curvature modes are tested experimentally up to failure under the effect of different end eccentricities combinations. Three end eccentricities ratio were studied, namely, $0.1 b, 0.3 b$ and $0.5 b$, where $b$ is the column width. Second, an expression correlated the decay in the normalized axial capacity of the column and the acting end eccentricities was developed based on the experimental results and then verified against the available formula. Third, based on the equivalent column concept, the equivalent pin-ended columns were obtained for columns bent in either single or double curvature modes. And then, the effect of end eccentricity ratio was correlated to the equivalent column length. Finally, a simplified design procedure was proposed for eccentrically loaded braced column by transferring it to an equivalent axially loaded pin-ended slender column. The results of the proposed design procedure showed comparable results against the results of the ACI 318-14 code.
\end{abstract}

Keywords: columns, double curvature mode, eccentric loading, equivalent column concept, single curvature mode, reinforced concrete.

\section{Introduction}

Eccentrically loaded reinforced concrete columns are commonly exist in practice due to the existence of some bending moments. The eccentricity of the supported beams as well as the unavoidable imperfections of construction are the main sources of the developed bending moments in the columns under gravity loads. In addition, lateral loads due to wind or earthquake loading are another source of the developed bending moments on the columns. Therefore, the strength of the columns is controlled by the compressive strength of concrete, the tensile strength of the longitudinal reinforcements and the geometry of the column' cross-section (Park and Paulay 1975; Nilson 2004; McCormac 1998; Yalcin and Saatcioglu 2000; MacGregor and Wight 2009). Contrasting to reinforced concrete beams, the compression failure cannot be avoided for eccentrically loaded columns since the type of failure is mainly dependent on the axial load level (Park and Paulay 1975).

\footnotetext{
${ }^{1)}$ Department of Structural Engineering, Faculty of Engineering, Tanta University, Tanta 31511, Egypt. *Corresponding Author; E-mail:

Reinforced concrete columns are classified as short columns while the slenderness effect can be neglected or slender columns where the slenderness effect has to be included in the design. In order to distinguish between these two types, there are two important limits for slenderness ratio/index which are the lower and the upper slenderness limits. Most of the limit expressions provided by codes were derived assuming a certain loss of the column ultimate capacity due to the second order effect. Lower slenderness limits may be defined as the slenderness producing a certain reduction, usually $5-10 \%$, in the column ultimate capacity compared to that of a non-slender column (Mari and Hellesland 2005). Inspite that the lower slenderness limit of short column is mostly dependent on the adopted design standards. Figure 1 shows comparison among the limiting slenderness indices stipulated by the American Concrete Institute Code, ACI 318-14 (2014), the Canadian Standard Code, CSA A23.3-04 (R 2010) and the Egyptian Code of Practice, ECP 203-2007 (2007), where $H_{e}$ is the effective length of the column and $i$ is the radius of gyration of the column cross-section. It can be noted that the limit stipulated by the ACI 318-14 depends on the relative end moments, while the limit adopted by the CSA A23.3-04 depends on both the end moments ratio and the axial load level. On the other hand, the ECP 203-07 adopts a fixed limit for the upper slenderness limit for the short column regardless of the end moments, the axial load level and the concrete strength, in order to distinguish between the short and the slender column. 


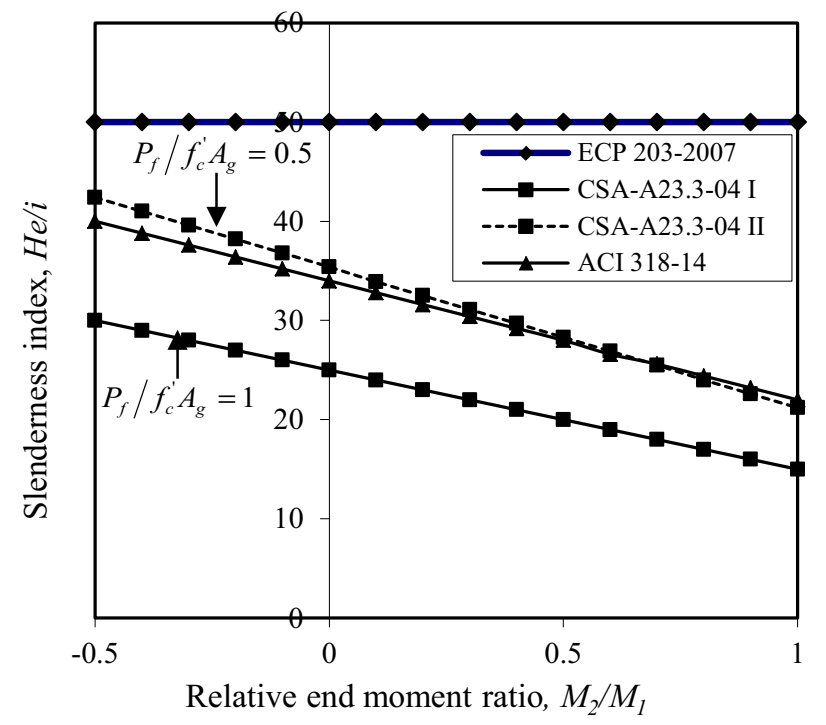

Fig. 1 Limitations of the upper slenderness limits for short column stipulated in different standards.

As for the upper slenderness limit, there is no explicit definition for that limit at most of the design standards (American Concrete Institute 2014; CAN/CSA-A23.3-04 (R2010) 2010; ECP 203-2007). In addition, the amount of reduction in the column capacity corresponding to that limit is not well defined. Although the upper slenderness limit can be considered as the limit required to avoid instability failure of the column (Ivanov 2004; Barrera et al. 2011). Despite this common basis, and even though most relevant factors governing the behavior of slender columns are well identified, a lack of uniformity can be observed in the conceptual treatment of the lower/upper slenderness limits in different codes. Not surprisingly, large differences may be obtained when applying the above code provisions. Also, there are different values of the lower/upper slenderness limits for columns based on the bracing conditions.

In this paper the proposed design approach is aimed to consider any imperfection on the original column as well as the acting end moments when designing the column. That can be done be transforming the original column considering any initial bending moments to an equivalent pin-ended axially loaded column. And then, the additional bending moment including the end eccentricities as well as slenderness effect can be calculated. Therefore, the lower slenderness ratio could be bypassed. In addition, in order to verify the instability failure of the column, the acting axial load on the equivalent column is compared with the critical buckling load of the column.

Hinged-ended columns braced against side-sway may be bent in either single or double curvature mode with loading depending on the direction of acting end moments as depicted in Fig. 2 (Park and Paulay 1975; Cranston 1972). For both curvature modes, the bending deformations cause additional bending moments that can affect the primary end moments. If the additional moments are large, the maximum moments may move from ends to within the height of the columns. Since the lateral deformation for the case of single curvature mode is greater than that of the double curvature mode, the maximum bending moment in the single curvature case is higher than that in the double curvature one (Park and Paulay 1975). Therefore, the greatest reduction in the ultimate load capacity will occur for the case of equal end eccentricities for columns bent in single curvature mode, while the smallest reduction will occur for the case of equal end eccentricities for columns bent in double curvature mode (MacGregor et al. 1970; Milner et al. 2001).

It is accepted that the deflected axis of any column may be represented by a portion of the column deflected shape of

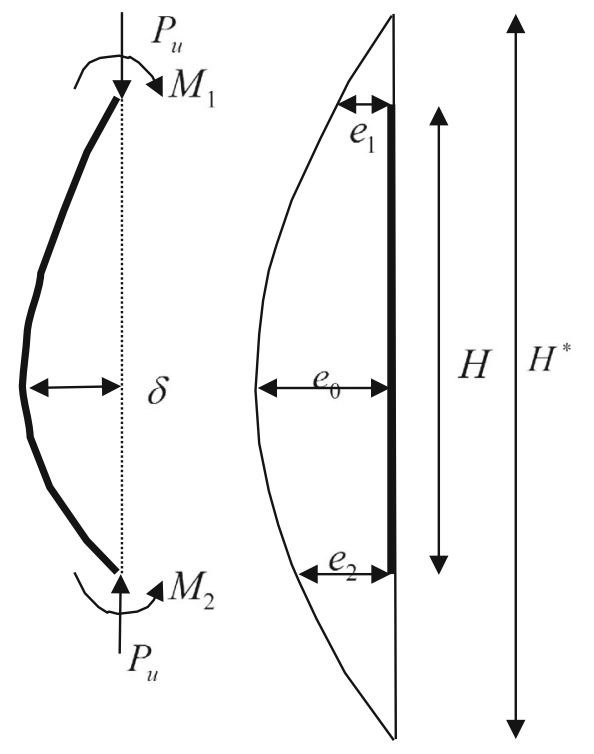

(a) Single curvature

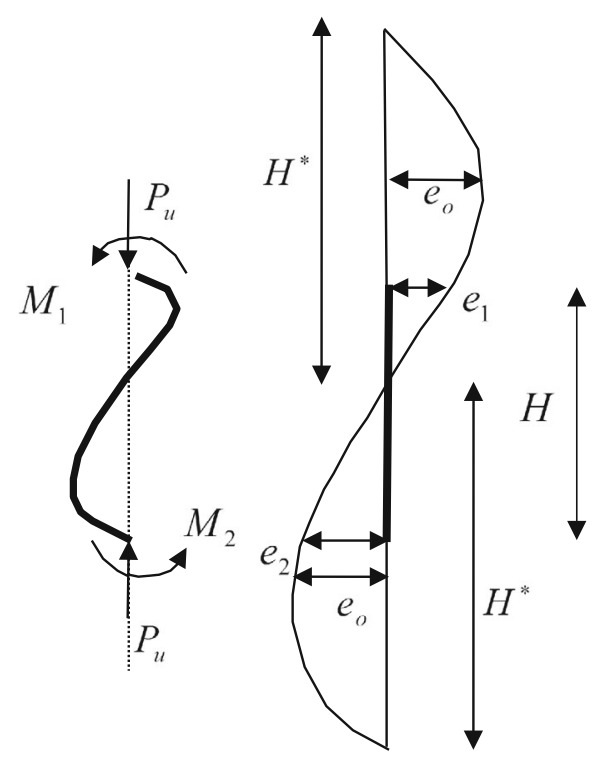

(b) Double curvature

Fig. 2 Curvature modes of RC columns under end eccentric loading. 
axially loaded pin-ended column (Chen and Lui 1987). Therefore, for a given column subjected to end moments, an equivalent column exists. Making use of Fig. 2, the column deflected shape of the equivalent pin-ended column can be represented by sinusoidal curve as illustrated in Eq. (1).

$$
e=e_{o} \sin \frac{\pi x}{H^{*}}
$$

where $e$ is the lateral deflection of the column at a distance $x$ from one end of the column, $H^{*}$ is the length of the equivalent pin-ended column and $e_{o}$ is the maximum deflection at the mid-height of the equivalent column that can be calculated using Eq. (2).

$$
e_{o}=\phi_{m} \frac{H^{* 2}}{\pi^{2}}
$$

where $\phi_{m}$ is the curvature of the column based on the column's mode of failure.

This concept is adopted in order to reduce uni-axially loaded column to an axially loaded equivalent pin-ended column with greater length (El-Metwally 1994; Afefy et al. 2009; Afefy 2012).

In the current paper, the behavior of eccentrically loaded column bent in both single and double curvature modes is studied experimentally. In addition, based on the experimental test results, an expression was derived in order to predict the capacity lost due to column end eccentricities. And then, the equivalent column concept is employed in order to switch eccentrically loaded columns bent in either single or double curvature mode to axially loaded pin-ended equivalent columns. The end eccentricity ratio is correlated to the equivalent column length. Finally, a simplified design procedure for eccentrically loaded braced columns is proposed and compared against the design procedure stipulate in the ACI 318-14 Code.

\section{Experimental Work Program}

\subsection{Test Columns}

The experimental work program included 15 reducedscale columns ( $1 / 3$ scale model) divided into 4 groups as well as a control axially loaded column. The first two groups represented columns bent in single curvature modes, while the remaining two groups represented columns bent in double curvature modes. For both curvature modes, equal and unequal end eccentricities combinations about minor axis were studied.

The nominal axial capacity of the column cross-section was about $600 \mathrm{kN}$ based on Eq. (3) as recommended by ACI 318-14.

$$
P_{o}=0.85 f_{c}^{\prime}\left(A_{c}-A_{s}\right)+A_{s} f_{y}
$$

where $P_{\mathrm{o}}$ is the nominal axial capacity of the column crosssection, $f_{c}^{\prime}$ is the concrete compressive cylinder strength, $f_{y}$ is the yield strength of the longitudinal steel bars, $A_{c}$ is the cross-sectional area of concrete section, and $A_{s}$ is the crosssectional area of the longitudinal steel bars.

It was noted that the usual end eccentricity value, $e / b$, for columns in reinforced concrete buildings is varying from 0.1 to 0.65 (Mirza and MacGregor 1982). In addition, recent researches showed that exposing the reinforced concrete column to an end eccentricity ratio more than half the column side exhibited drastic reduction in the ultimate capacity of the column (MacGregor et al. 1970; Milner et al. 2001; Chuang and Kong 1997; Afefy 2007). Hence, the studied end eccentricity ratios were chosen to be $0.1,0.3$ and 0.5 .

Table 1 summarizes the details of the tested columns. The column cross-section was $100 \mathrm{~mm}$ width by $150 \mathrm{~mm}$ length and the overall height of $1200 \mathrm{~mm}$. The column longitudinal reinforcement was four deformed bars of $10 \mathrm{~mm}$ diameter corresponding to reinforcement ratio of $2.09 \%$. The stirrups were made from mild smooth bars of $6 \mathrm{~mm}$ diameter spaced every $100 \mathrm{~mm}$, while both ends were provided by additional stirrups as depicted in Fig. 3a.

All specimens were cast horizontally in wooden forms. Two days after casting, the standard cubes and the sides of the specimens were stripped from the molds and covered with plastic sheets until the seventh day, when the plastic sheets were removed and the specimens allowed air-drying until testing day.

\subsection{Material Properties}

The used concrete was normal strength concrete of $40 \mathrm{MPa}$ target cube strength, which was the average of three standard cubes of $150 \mathrm{~mm}$ side length. The cement used was normal Portland cement (Type I) with $4.75 \mathrm{kN} / \mathrm{m}^{3}$ cement content and the water to cement ratio was kept as 0.38 . The concrete mix contained type I crushed pink limestone as the coarse aggregates whose maximum aggregate size was $10 \mathrm{~mm}$. The sand was supplied from a local plant around the site and its fineness modulus was $2.7 \%$. The volumes of limestone and sand in one cubic meter were 0.73 and 0.37 , respectively. The average concrete strength at the testing day of columns was $42.89 \mathrm{MPa}$, while the test of all columns had been carried out in two consecutive days.

In order to determine the mechanical properties of the longitudinal deformed steel bars of $10 \mathrm{~mm}$ diameter as well as the transverse smooth bars of $6 \mathrm{~mm}$ diameter, tensile tests were performed on three specimens for each bar size. For the $10 \mathrm{~mm}$ deformed bars, the mean value of tensile yield strength, ultimate strength and Young's modulus were $418 \mathrm{MPa}, 580 \mathrm{MPa}$ and $202 \mathrm{GPa}$, respectively, while the relevant values for the $6 \mathrm{~mm}$ mild steel bars were $250 \mathrm{MPa}$, $364 \mathrm{MPa}$ and $205 \mathrm{GPa}$, respectively. The used steel to form the pile caps in order to facilitate the application of eccentric loading at both ends of columns was mild steel of $12 \mathrm{~mm}$ thickness and yield strength of $280 \mathrm{MPa}$.

\subsection{Test Setup and Instrumentation}

Steel rig had been fabricated and assembled at the Reinforced Concrete Laboratory of the Faculty of Engineering, Alexandria University, Alexandria, Egypt, in order to facilitate the execution of the experimental work program. Steel 
Table 1 Test matrix.

\begin{tabular}{|c|c|c|c|c|c|c|}
\hline \multirow[t]{2}{*}{ Group no. } & \multirow[t]{2}{*}{ Column } & \multicolumn{2}{|c|}{ Eccentricity at upper end } & \multicolumn{2}{|c|}{ Eccentricity at lower end } & \multirow[t]{2}{*}{ Curvature mode } \\
\hline & & $\mathrm{mm}$ & $e / b$ & $\mathrm{~mm}$ & $e / b$ & \\
\hline Control & C-0-0 & 0.0 & $0 . .0$ & 0.0 & 0.0 & \\
\hline \multirow[t]{3}{*}{1} & S-1-1 & 10 & 0.1 & 10 & 0.1 & \multirow[t]{9}{*}{ Single } \\
\hline & S-3-3 & 30 & 0.3 & 30 & 0.3 & \\
\hline & S-5-5 & 50 & 0.5 & 50 & 0.5 & \\
\hline \multirow[t]{6}{*}{2} & S-0-1 & 10 & 0.1 & 0.0 & 0.0 & \\
\hline & S-1-3 & 30 & 0.3 & 10 & 0.1 & \\
\hline & S-1-5 & 50 & 0.1 & 10 & 0.5 & \\
\hline & S-0-3 & 30 & 0.3 & 0.0 & 0.0 & \\
\hline & S-3-5 & 50 & 0.5 & 30 & 0.3 & \\
\hline & S-5-0 & 50 & 0.5 & 0.0 & 0.0 & \\
\hline \multirow[t]{3}{*}{3} & D-1-1 & 10 & 0.1 & 10 & 0.1 & \multirow[t]{6}{*}{ Double } \\
\hline & D-3-3 & 30 & 0.3 & 30 & 0.3 & \\
\hline & D-5-5 & 50 & 0.5 & 50 & 0.5 & \\
\hline \multirow[t]{3}{*}{4} & D-1-3 & 30 & 0.3 & 10 & 0.1 & \\
\hline & D-1-5 & 50 & 0.5 & 10 & 0.1 & \\
\hline & D-3-5 & 50 & 0.5 & 30 & 0.3 & \\
\hline
\end{tabular}

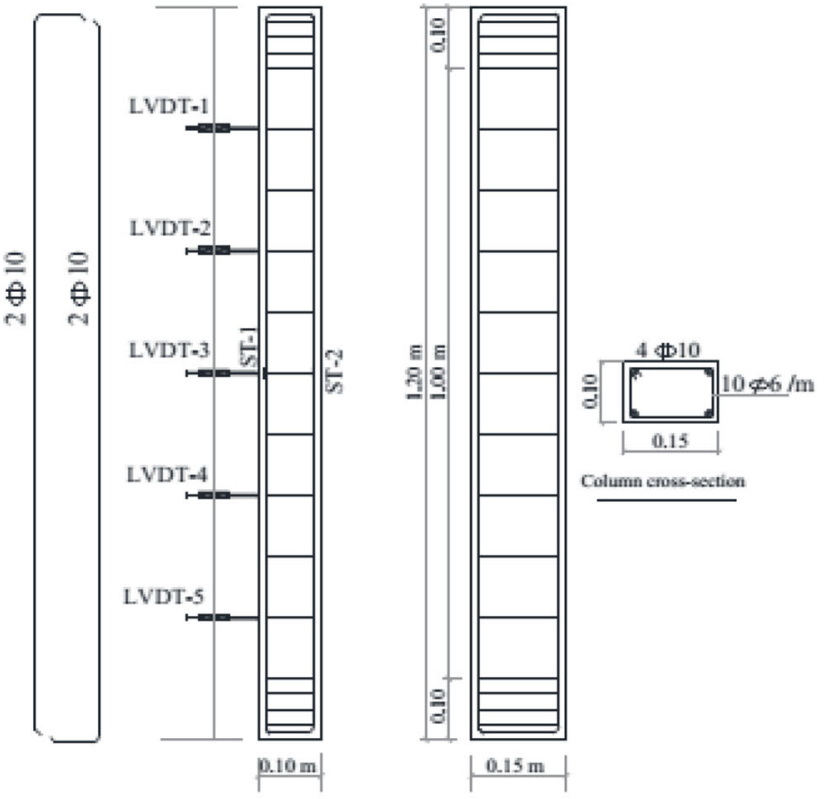

(a) Concrete dimensions and reinforcement detailing

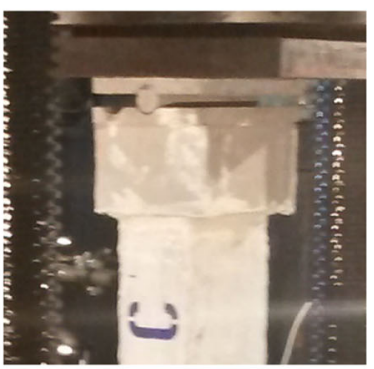

(b) Upper support

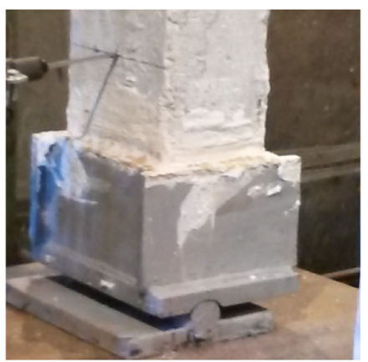

(c) Lower support

Fig. 3 Concrete dimensions, reinforcement detailing and supports details for typical column.

caps were provided at both ends of the column in order to distribute the column compression load at both ends as well as to facilitate the application of eccentric loading. Figures $3 \mathrm{~b}$ and $3 \mathrm{c}$ show both supports, while the column was loaded using compression test machine of $3000 \mathrm{kN}$ capacity. Five $100 \mathrm{~mm}$ LVDTs were used in order to measure the lateral deformation about the minor axis as depicted in Fig. 3. Hence, the final deformed shape can be obtained. In addition, 2 strain gauges of $6 \mathrm{~mm}$ gauge length were mounted on the mid-height of the column longitudinal bars in order to measure the developed normal strain at the midheight section. Load was applied in a force-control protocol 
to the column through moving lower head of the testing machine incrementally every $5 \mathrm{kN}$. The loading was continued until the specimen cannot sustain further loading. After each loading step, the acting loads on the column, the strain gauges readings and the LVDTs readings were recorded. An automatic data logger unit had been used in order to record and store data during the test for load cells, strain gauges and the LVDTs.

\subsection{Specimen Nomenclature}

Table 1 presents test parameters and the associated specimen descriptions. The specimen nomenclature consists of 3 symbols separated by hyphens. The first symbol indicates the curvature mode $(\mathrm{S}=$ single curvature, $\mathrm{D}=$ double curvature). The second nomenclature stands for amount of lower end eccentricity $(0=$ concentric loading, $1=10 \mathrm{~mm}$ end eccentricity, $3=30 \mathrm{~mm}$ end eccentricity, $5=50 \mathrm{~mm}$ end eccentricity). The third number indicates the same end eccentricity as presented in the second nomenclature but for the upper end. For instance, S-1-5 can be interpreted as follows: $\mathrm{S}=$ single curvature; $1=$ the eccentricity at lower end $=10 \mathrm{~mm} ; \quad 5=$ the eccentricity at the upper end $=50 \mathrm{~mm}$.

\section{Results and Discussion}

The test results of the concentrically loaded column as well as eccentrically loaded columns under the effect of different end eccentricities combinations are presented and discussed in detailed. In general, all eccentrically loaded columns sustained ultimate loads lower than that sustained by the concentrically loaded column. In addition, the ultimate load reduction for columns bent in single curvature modes were higher than those of the columns had the same end eccentricities but bent in double curvature modes. A summary of the test results is given in Table 2 and further discussed is presented including modes of failure, deformed shapes, ultimate capacity and developed normal strain on the longitudinal bars at the mid-height section.

\subsection{Modes of Failure}

The failure of axially loaded column C-0-0 was sudden compressive failure since after yielding of the longitudinal steel bars in compression, the concrete had been crushed at the upper half of the column. The application of equal end eccentricities as for columns S-1-1, S-3-3 and S-5-5 resulted in employing constant moment along the entire height of the column. For columns S-1-1 and S-3-3, cracks began to appear very close to the ultimate load near the mid-height section. On the other hand, increasing the end eccentricity to be $0.5 b$ resulted in regular flexural failure. For column S-5-5, cracks began to appear at the tensile side at acting load of about $62 \%$ of the failure load. With further loading, cracks spread on the tensile side till the concrete crushed at the compression side near the mid-height section. Figure 4 shows the failed columns of group No. 1.
For the case of unequal end eccentricities, failure was either regular tension failure or sudden flexural failure (compression failure). Cracks began to appear near the end support of the higher end eccentricity, and then failure was triggered by concrete crushing at such support. For all cases of end eccentricity of $0.5 b$, cracks appeared at the tension side near the end support at acting load of about $82 \%$ of the failure load, while for other end eccentricities $(0.1 b$ and $0.3 b$ ) cracks appeared at a vertical load very close to the failure load. Figure 5 depicts the failure shapes for all columns of group No. 2.

For all columns bent in double curvature mode, failures were similar to the case of single curvature modes with unequal end eccentricities where all columns failed near the end support of the higher end eccentricity in flexural mode of failure. Figures 6 and 7 show the failure shapes for all columns of groups No. 3 and No. 4. It can be noted that column bent in double curvature mode sustained higher load than the opponent column bent in single curvature mode. For instance, columns D-1-3, D-1-5, and D-3-5 sustained ultimate loads of 480,300 , and $379 \mathrm{kN}$, respectively, while columns S-1-3, S-1-5 and S-3-5 sustained ultimate loads of 395,245 , and $220 \mathrm{kN}$, respectively. That can be attributed to that the section of the maximum lateral deformation due to axial compression is around the mid-height point, while this location has minimal effect of bending moment for column bent in double curvature mode. On the other hand, for column bent in single curvature mode, this location, mid-height section, has considerable bending moment, which magnifies the primary moment on the column leading to lower sustained load.

\subsection{Deformed Shapes}

The measured deformed shapes about minor axis for all columns near failure are depicted in Fig. 8. Figures $8 \mathrm{a}, \mathrm{b}$ show the deformed shapes for columns bent in single curvature modes. It can be noted that inspite the column $\mathrm{C}-0-0$ was consider as short column it exhibited slight lateral deformation of about $0.03 \mathrm{~b}$. This value is within the limits stipulated by the Egyptian Code of Practice, ECP 203-2007. This limit states that the upper limit for short column in order to neglect the slenderness effect is $0.05 b$. Increasing the equal end eccentricities to be $10 \mathrm{~mm}(\mathrm{~S}-1-1)$ resulted in increased the measured lateral deformation by about $0.05 b$ compared to that of the axially loaded column (C-0-0). Increasing the end eccentricities to be $30 \mathrm{~mm}$ (S-3-3) resulted in increased lateral deformation by about $0.06 \mathrm{~b}$. Increasing the end eccentricities further to $50 \mathrm{~mm}$ (S-5-5) resulted in increased lateral deformation by about $0.12 b$. The measured lateral deformations of all columns having equal end eccentricities and bent in single curvature mode were approximately symmetrical about the mid-height point as depicted in Fig. 8a. As for the case of unequal end eccentricities, the maximum value for the measured lateral deformation was bias to the end having the higher end eccentricity as depicted in Fig. 8b. For the case of columns bent in single curvature mode, the upper bound was 
Table 2 Experimental results.

\begin{tabular}{|c|c|c|c|c|c|c|c|}
\hline \multirow[t]{2}{*}{ Group no. } & \multirow[t]{2}{*}{ Column } & \multirow[t]{2}{*}{$\begin{array}{l}\text { Cracking load, } \\
\text { kN }\end{array}$} & \multirow[t]{2}{*}{ Failure load, kN } & \multicolumn{2}{|c|}{$\begin{array}{c}\text { Maximum measured steel strain at } \\
\text { mid-height, micro-strain }\end{array}$} & \multirow[t]{2}{*}{$\begin{array}{c}\text { Maximum lateral } \\
\text { deflection, } \mathrm{mm}\end{array}$} & \multirow[t]{2}{*}{$\begin{array}{l}\text { Dominant mode } \\
\text { of failure }\end{array}$} \\
\hline & & & & Compressive & Tensile & & \\
\hline Control & $\mathrm{C}-0-0$ & NA & 675 & 2247 & NA & 3.06 & $\begin{array}{l}\text { Sudden } \\
\text { compressive }\end{array}$ \\
\hline \multirow[t]{3}{*}{1} & S-1-1 & NA & 450 & 2326 & NA & 7.72 & $\begin{array}{l}\text { Compression } \\
\text { failure }\end{array}$ \\
\hline & S-3-3 & 270 & 300 & 2063 & 3453 & 8.91 & Tension failure \\
\hline & S-5-5 & 105 & 170 & 980 & 2362 & 14.77 & Tension failure \\
\hline \multirow[t]{6}{*}{2} & S-0-1 & NA & 530 & 1982 & NA & 2.72 & $\begin{array}{l}\text { Compression } \\
\text { failure }\end{array}$ \\
\hline & S-1-3 & NA & 395 & 1809 & NA & 8.47 & $\begin{array}{l}\text { Compression } \\
\text { failure }\end{array}$ \\
\hline & S-1-5 & 210 & 245 & 1103 & 474 & 7.60 & Tension failure \\
\hline & S-0-3 & NA & 410 & 1612 & NA & 4.04 & $\begin{array}{l}\text { Compression } \\
\text { failure }\end{array}$ \\
\hline & S-3-5 & 180 & 220 & 1157 & 958 & 11.37 & Tension failure \\
\hline & S-5-0 & 220 & 265 & 856 & 446 & 5.65 & Tension failure \\
\hline \multirow[t]{3}{*}{3} & D-1-1 & NA & 580 & 1460 & NA & 2.82 & $\begin{array}{l}\text { Compression } \\
\text { failure }\end{array}$ \\
\hline & D-3-3 & 300 & 473 & 1004 & NA & 5.40 & Tension failure \\
\hline & D-5-5 & 250 & 416 & 528 & NA & 4.90 & Tension failure \\
\hline \multirow[t]{3}{*}{4} & D-1-3 & NA & 480 & 1321 & NA & 2.56 & $\begin{array}{l}\text { Compression } \\
\text { failure }\end{array}$ \\
\hline & D-1-5 & 180 & 300 & 905 & NA & 5.77 & Tension failure \\
\hline & D-3-5 & 240 & 379 & 569 & NA & 4.57 & Tension failure \\
\hline
\end{tabular}

$N A$ not applicable.

exhibited by column S-5-5, while the lower bound was manifested by axially loaded column $\mathrm{C}-0-0$.

For columns bent in double curvature mode, it can be noted that the columns showed un-symmetric deformed shape compared to initial center line of the column. However, when consider the final deformed shape due to axial load as exhibited by column C-0-0, the final deformed shapes showed symmetric configuration with respect to the deformed shape of column C-0-0, for the case of equal end eccentricities as depicted in Fig. 8c. As for unequal end eccentricities, the maximum lateral deformations were shifted to the end having the higher end eccentricity as shown in Fig. 8d.

Figure 9a shows the relationships between the vertical load and the developed lateral deflection at the mid-height section for all columns of Group No. 1. It can be noted that increasing the end eccentricity ratio resulted in decreasing the ultimate load carrying capacity and increasing the corresponding lateral defection. The column S-5-5 showed the highest reduction in the ultimate capacity as well as the highest lateral deflection among all columns subjected to different end eccentricity combinations and bent in either single or double curvature modes as depicted in Figs. 9b, c.
For columns having unequal end eccentricity combinations bent in single curvature modes and the columns bent in double curvature modes the maximum lateral deflections were noticed to be developed at the upper half of the columns as shown in Fig. 8. Therefore, the lateral deflections for those columns were presented at a distance 0.67 of the column height as depicted in Figs. $9 \mathrm{~b}$ and 9c. It can be observed that the columns bent in double curvature modes showed higher ultimate capacity and lower lateral defections than those of columns bent in single curvature modes and having the same end eccentricities combinations.

\subsection{Ultimate Capacity}

Table 2 summarizes the ultimate sustained loads for all columns. It can be noted that the highest ultimate capacity exhibited by the concentrically loaded column $\mathrm{C}-0-0$, while the lowest ultimate capacity was achieved by column S-5-5 having single curvature mode and equal end eccentricities of $0.5 b$, as expected. The column S-5-5 sustained only $25 \%$ of the relevant capacity of concentrically loaded column C-0-0. This means that with further end eccentricity the column will drop its normal capacity significantly. 


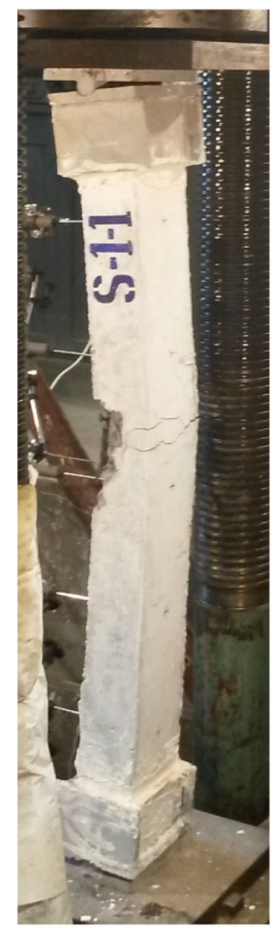

(a) S-1-1

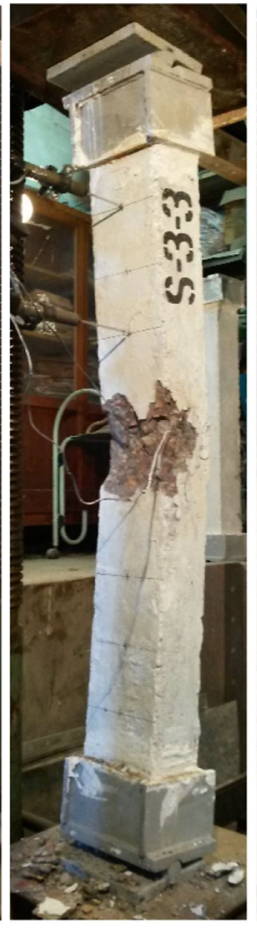

(b) $\mathrm{S}-3-3$

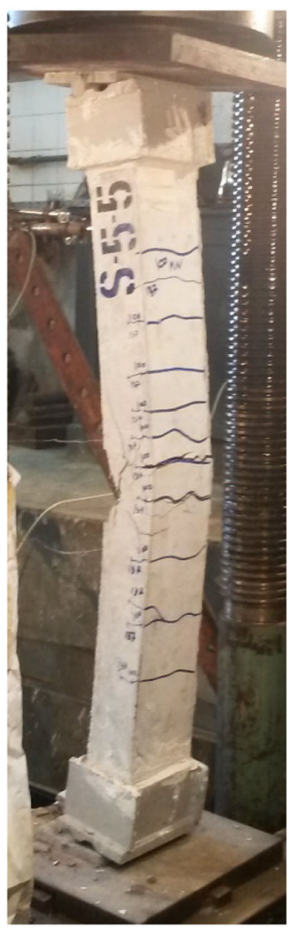

(c) $\mathrm{S}-5-5$
Fig. 4 Final failure modes for all columns of group No. 1.

In order to assist the effect of end eccentricity on the ultimate capacity of eccentrically loaded columns, an expression is proposed based on the experimental results as given by Eq. (4).

$$
P_{u}=P_{o} e^{-2 . .9\left(\frac{e}{b}\right)}
$$

where $P_{u}$ is the ultimate capacity, $P_{o}$ is the nominal capacity of the column cross-section, which considered in the current study as the ultimate capacity of concentrically loaded column $\mathrm{C}-0-0, e / b$ is the ratio between the equal end eccentricity and the column side. However, this expression was derived for columns subjected to equal end eccentricities, i.e., the maximum moment occurs at the mid-height point of the column. For the column subjected to unequal end moments and bent in either single or double curvature mode, the maximum moment may occur at the column's end or somewhere within the column. For such cases, the concept of equivalent moment could be implemented.

For a column subjected to end moments $M_{1}$ and $M_{2}$, where $M_{2}$ is greater than $M_{1}$, the magnitude of the equivalent moment, $M_{e q}$, is such that the maximum moment produced by it will be equal to that produced by the actual end moments $M_{1}$ and $M_{2}$ as depicted in Fig. 10. Austin (Chen and Lui 1987) proposed a general expression for the equivalent moment that gives the same effect at the midheight of the column as given by Eq. (5).

$$
M_{e q}=0.6 M_{2}-0.4 M_{1} \geq 0.4 M_{2}
$$

where $M_{1}$ has a negative value for column bent in single curvature mode. Since the equivalent end eccentricity can be obtained by dividing the equivalent moment by the acting normal force on the column, the equivalent end eccentricity, $e_{e q}$, can be obtained from Eq. (6).

$$
e_{e q}=0.6 e_{2}-0.4 e_{1} \geq 0.4 e_{2}
$$

where $e_{1}$ and $e_{2}$ are the corresponding end eccentricities for moments $M_{1}$ and $M_{2}$, respectively.

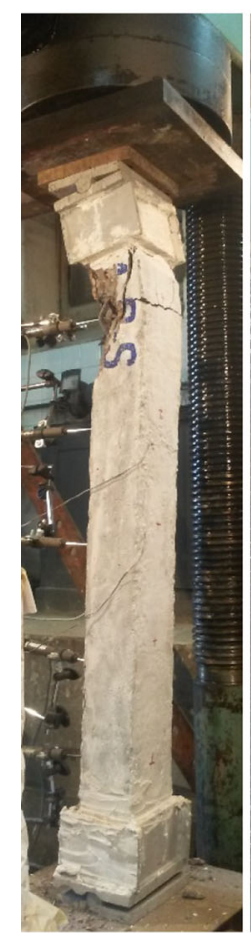

(a) S-0-1

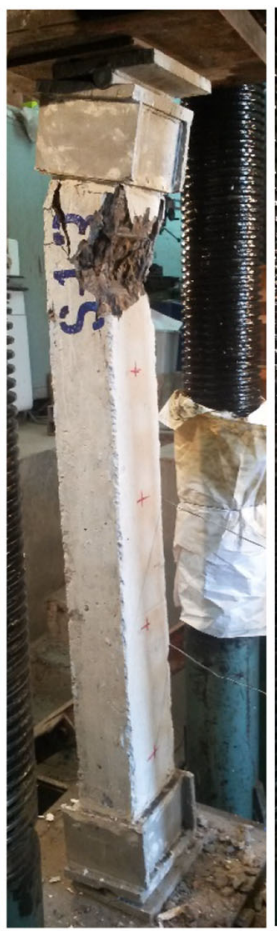

(b) $\mathrm{S}-1-3$

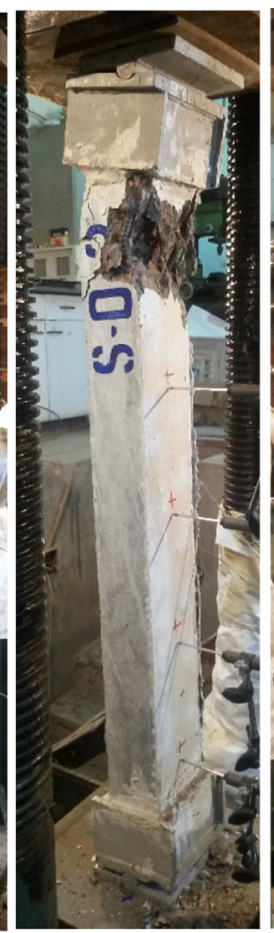

(c) $\mathrm{S}-0-3$

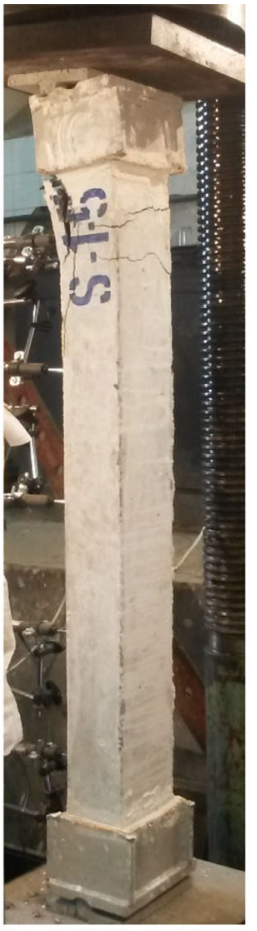

(d) $\mathrm{S}-1-5$

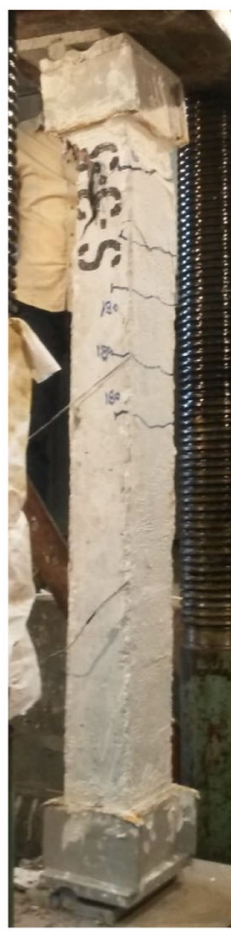

(e) $\mathrm{S}-3-5$

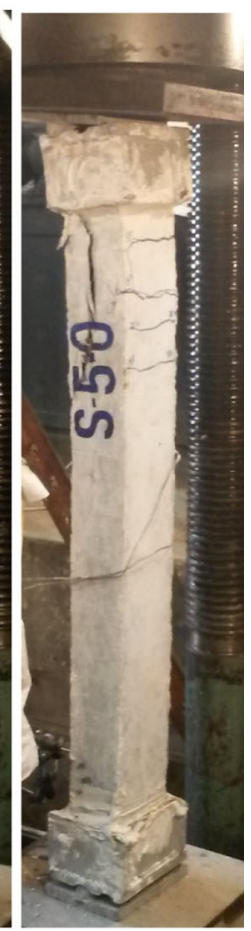

(f) $\mathrm{S}-5-0$

Fig. 5 Final failure modes for all columns of group No. 2. 


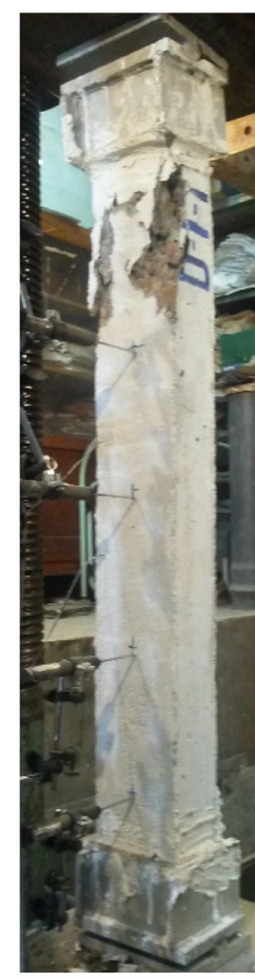

(a) D-1-1

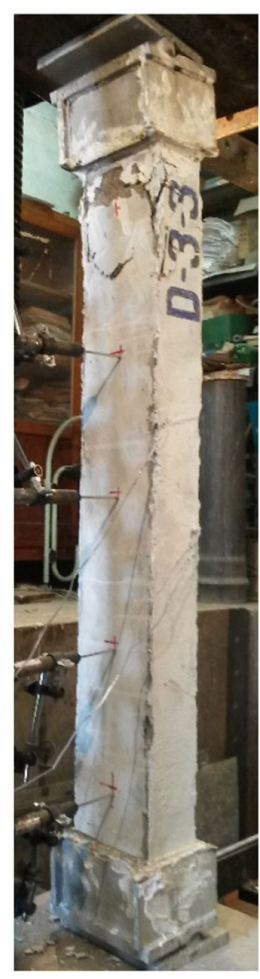

(b) D-3-3 (c) D-5-5

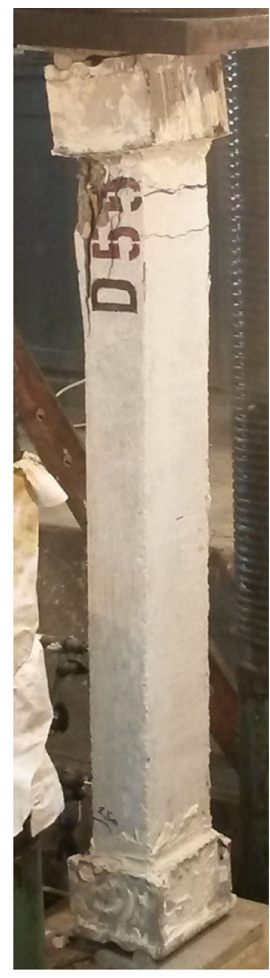

Fig. 6 Final failure modes for all columns of group No. 3.

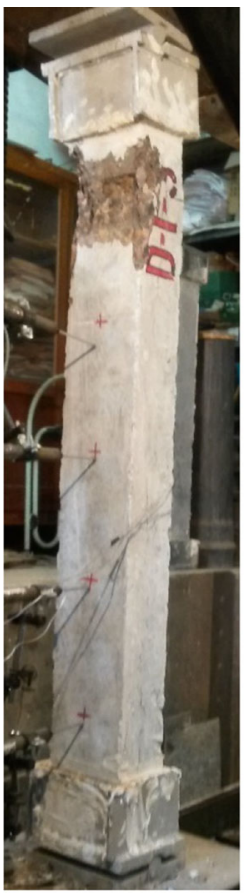

(a) D-1-3

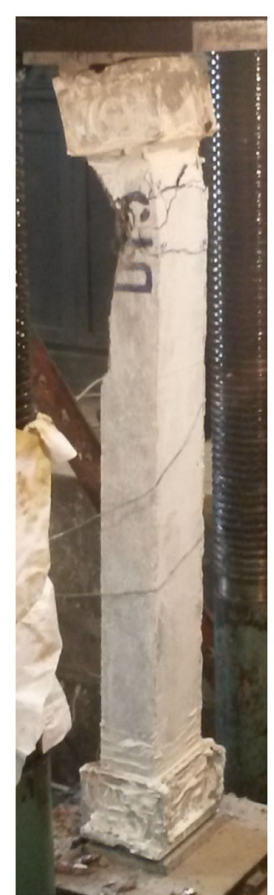

(b) D-1-5

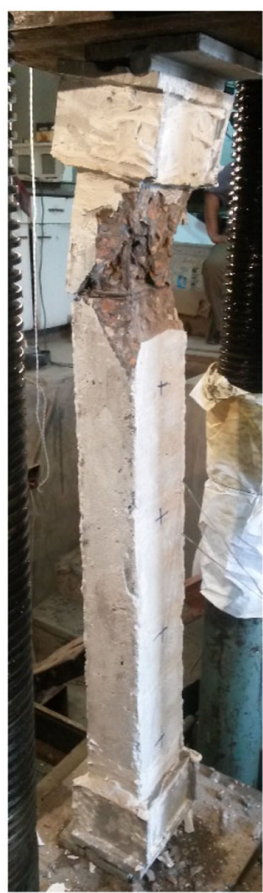

(c) D-3-5
Fig. 7 Final failure modes for all columns of group No. 4.

Table 3 lists normalized capacities based on both experimental findings and those obtained from the proposed expression. It can be noted that the coefficient of variation was 0.0941 . In addition, the maximum variation is ranging from $-10 \%$ to $+21 \%$, while in most cases small variations were recorded. This indicated that the proposed expression can predict well the ultimate capacities of eccentrically loaded columns bent in either single or double curvature modes.

Furthermore, the proposed expression based on experimental tests was compared with the proposed expression by Afefy (2012). Based on about 400 test results from literature, Afefy proposed Eq. (7) in order to correlate the normalized axial capacity and the end eccentricity ratio $e / b$.

$$
P_{u}=P_{o} e^{-2.4\left(\frac{e}{t}\right)}
$$

Figure 11 shows comparison between both expressions. It can be concluded that the proposed expression based on experimental test results showed more conservative results within about $10 \%$ compared to that presented by Afefy (2012).

\subsection{Developed Normal Strain on the Longitudinal Bars at the Mid-height Section}

Inspite that the maximum stressed section was not the same for all tested columns depending on the end eccentricities combinations, the developed normal strains on the longitudinal bars were measured at the mid-height section. Based on the used steel type, the yield strain of the longitudinal bars is 2069 micro-strain. Since the column C-0-0 was short in both directions, i.e., the effect of slenderness is minimal, the developed strains along the entire height of the reinforcing bars should reach the yielding point at failure. That happened, as expected, where the measured compressive strain near failure was 2247 micro-strain for column C-0-0.

The application of end eccentricities at column ends changed the strain distribution along the column cross-section at the mid-height point, where tensile strain maybe developed based on the end eccentricity value as well as the curvature mode. For columns bent in single curvature modes, tensile strain could be developed at the mid-height section since this section is the maximum stressed section for the case of equal end eccentricities. While, for unequal end eccentricities, the maximum stressed section could be shifted based on the end eccentricities combinations. On the other hand, for the columns bent in double curvature modes, the mid-height section could develop the lowest strain for the case of equal end eccentricities and higher values but not the maximum ones for the case of unequal end eccentricities.

For group No. 1, only column S-1-1 developed compressive strain along the entire cross-section with a maximum value exceeded the yielding strain (2326 micro-strain). This can be attributed to small end eccentricities, which resulted in subjecting the column cross-section to non-uniform compressive stress. Increasing the end eccentricity to $30 \mathrm{~mm}$, resulted in increasing the acting bending moment. Hence, tensile stress was developed and the measured tensile strain exceeded the yielding point (3453 micro-strain). Increasing the end eccentricity further to $50 \mathrm{~mm}$, showed the same behavior as exhibited by column S-3-3 but the measured tensile strain was lower than that developed by column S-3-3 inspite that the acting moment was greater. That can be attributed to the lower sustained load by column S-5-5 


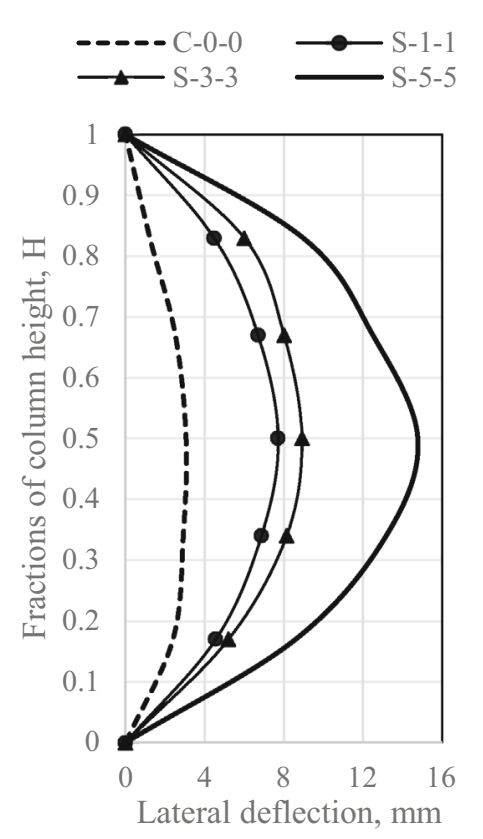

(a) Group No. 1

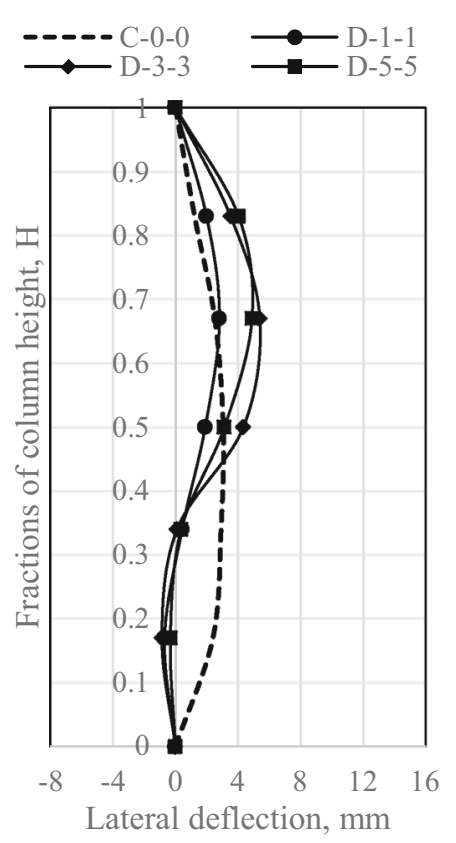

(c) Group No. 3

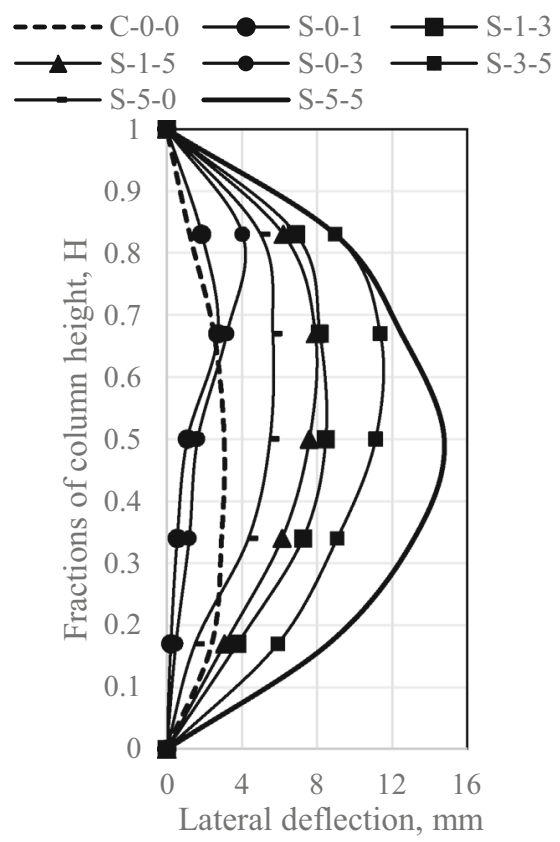

(b) Group No. 2

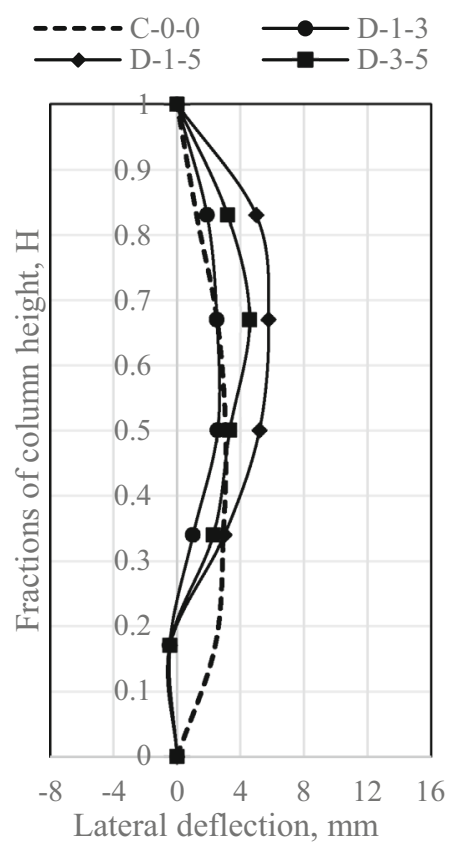

(d) Group No. 4

Fig. 8 Deformed shapes of all tested columns.

compared to that of column S-3-3. It can be noted that increasing the end eccentricities resulted in decrease the manifested compressive strains. That is owing to the decrease of the effect of normal force compared to the increased effect of the bending moment due to increased end eccentricities.

For columns having unequal end eccentricities of group No. 2, none of them reached the yielding point of the longitudinal steel bars on either tension or compression sides. That is because the maximum stressed section was shifted away from the measured locations. In all cases, the maximum stressed sections were located at the upper quarter of the tested column as depicted in Fig. 4. As shown in
Table 2, only the columns of $50 \mathrm{~mm}$ end eccentricity developed tensile strain on the longitudinal bars at the midheight point.

As for columns bend in double curvature modes as groups No. 3 and 4, none of them developed tensile strain in the longitudinal bars at the mid-height section. That can be attributed to the minimal effect of the developed bending moment at these sections, where the maximum stressed section were near the supports as depicted in Figs. 5 and 6. As illustrated in Table 2, it can be noted that increasing the end eccentricities resulted in decreasing the developed compressive strain on the longitudinal bars at the mid-height section due to increase the bending moment effect. 


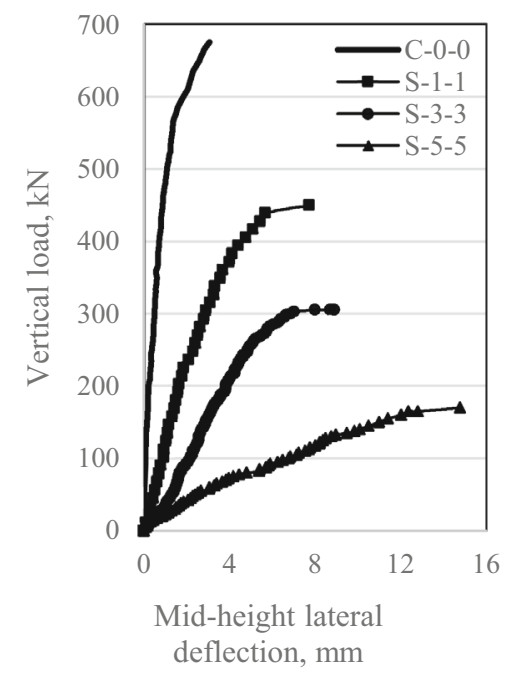

(a) Group No. 1

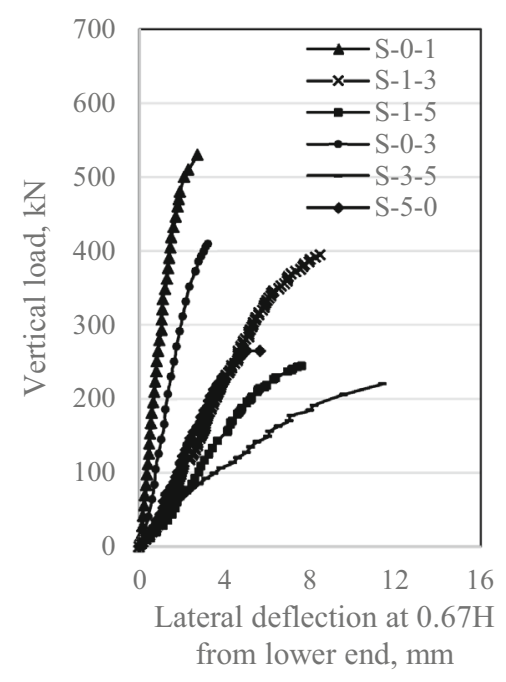

(b) Group No. 2

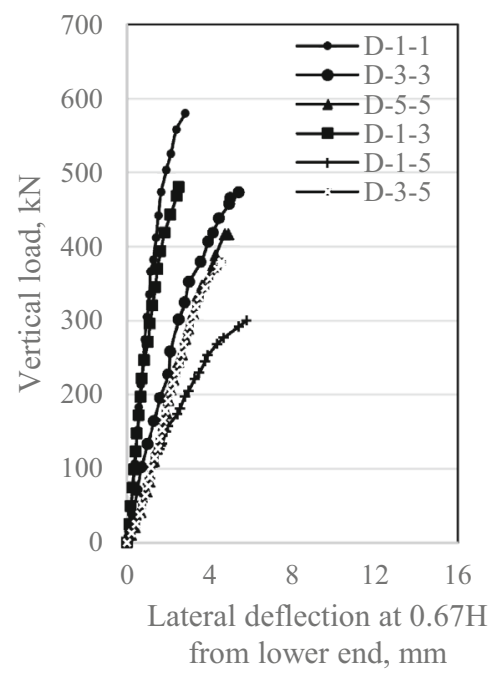

(c) Groups No. 3 and 4

Fig. 9 Vertical load versus lateral deflection for all tested columns.

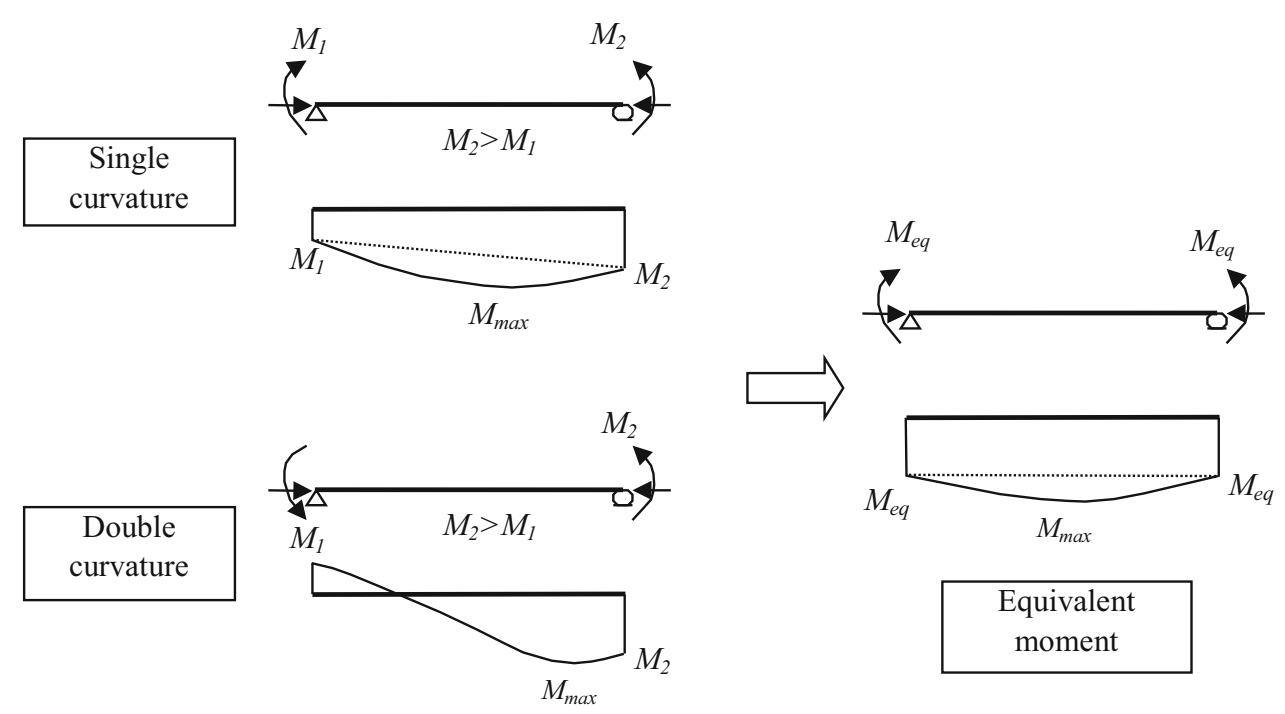

Fig. 10 Schematic representation of the concept of equivalent moment.

\subsection{Equivalent Column}

The relationship between the equivalent pin-ended column, $H^{*}$, and the end eccentricity is given in Eq. (1). Assuming balanced failure of the column, the curvature at the mid-height section of the equivalent column, $\phi_{m}$, can be represented by Eq. (8).

$$
\phi_{m}=\frac{\varepsilon_{c u}+\varepsilon_{y}}{b-c}
$$

where $\varepsilon_{c u}$ is the concrete crushing strain $=0.003, \varepsilon_{y}$ is the steel yield strain, equals yield stress divided by steel modulus of elasticity, and $c$ is concrete cover. Hence the maximum mid-height eccentricity can be rewritten as given in Eq. (9).

$$
e_{o}=\frac{\varepsilon_{c u}+\varepsilon_{y}}{b-c} \times \frac{H^{* 2}}{\pi^{2}}
$$

Knowing the end eccentricity value as well as the curvature mode, the equivalent column could be obtained.

\subsubsection{Implementation of the Equivalent Column Concept on Column Bend in Single Curvature Mode}

Consider column S-3-5 as an example for column bent in single curvature mode, the equivalent pin-ended axially loaded column is determined in the following, refer to Fig. 12a.

$$
\begin{aligned}
& e=e_{o} \sin \left(\frac{\pi x}{H^{*}}\right) \\
& e_{o}=\frac{\varepsilon_{c u}+\varepsilon_{y}}{b-c} \times \frac{H^{* 2}}{\pi^{2}}=0.00000568 H^{* 2}, \\
& e_{2}=50 \mathrm{~mm}, e_{1}=30 \mathrm{~mm} \\
& e_{1}=0.00000568 H^{* 2} \sin \left(\frac{\pi x_{1}}{H^{*}}\right)=30 \rightarrow(1) \\
& e_{2}=0.00000568 H^{* 2} \sin \left(\frac{\pi x_{2}}{H^{*}}\right)=50 \rightarrow(2) \\
& x_{2}=x_{1}+1200 \rightarrow(3)
\end{aligned}
$$

Solving the three equations by trial and error yields 
Table 3 Calculated axial load capacities versus experimental results.

\begin{tabular}{|c|c|c|c|c|c|c|c|}
\hline Group no. & Specimen & Failure load, kN & $\begin{array}{c}\text { Equivalent } \\
\text { eccentricity, } \mathrm{mm}\end{array}$ & Equivalent e/t & $\begin{array}{c}\text { Normalized load } \\
\text { based on } \\
\text { experimental } \\
\text { results }(6) \\
\end{array}$ & $\begin{array}{c}\text { Normalized load } \\
\text { based on Eq. (4) } \\
\text { (7) }\end{array}$ & $(7) /(6)$ \\
\hline Control & C- $0-0$ & 675 & 0.0 & 0.00 & 1.00 & 1.00 & 1.00 \\
\hline 1 & S-1-1 & 450 & 10 & 0.10 & 0.67 & 0.75 & 1.12 \\
\hline & S-3-3 & 300 & 30 & 0.30 & 0.44 & 0.42 & 0.94 \\
\hline & S-5-5 & 170 & 50 & 0.50 & 0.25 & 0.23 & 0.93 \\
\hline 2 & S-0-1 & 530 & 6 & 0.06 & 0.79 & 0.84 & 1.07 \\
\hline & S-1-3 & 395 & 22 & 0.22 & 0.59 & 0.53 & 0.90 \\
\hline & S-1-5 & 245 & 34 & 0.34 & 0.36 & 0.37 & 1.03 \\
\hline & S-0-3 & 410 & 18 & 0.18 & 0.61 & 0.59 & 0.98 \\
\hline & S-3-5 & 220 & 42 & 0.42 & 0.33 & 0.30 & 0.91 \\
\hline & S-5-0 & 265 & 30 & 0.30 & 0.39 & 0.42 & 1.07 \\
\hline 3 & D-1-1 & 580 & 2 & 0.02 & 0.86 & 0.94 & 1.10 \\
\hline & D-3-3 & 473 & 6 & 0.06 & 0.70 & 0.84 & 1.20 \\
\hline & D-5-5 & 416 & 10 & 0.10 & 0.62 & 0.75 & 1.21 \\
\hline 4 & D-1-3 & 480 & 14 & 0.14 & 0.71 & 0.67 & 0.94 \\
\hline & D-1-5 & 300 & 26 & 0.26 & 0.44 & 0.47 & 1.06 \\
\hline & D-3-5 & 379 & 18 & 0.18 & 0.56 & 0.59 & 1.06 \\
\hline \multicolumn{7}{|c|}{ Average } & 1.03 \\
\hline \multicolumn{7}{|c|}{ Coefficient of variation } & 0.0941 \\
\hline
\end{tabular}

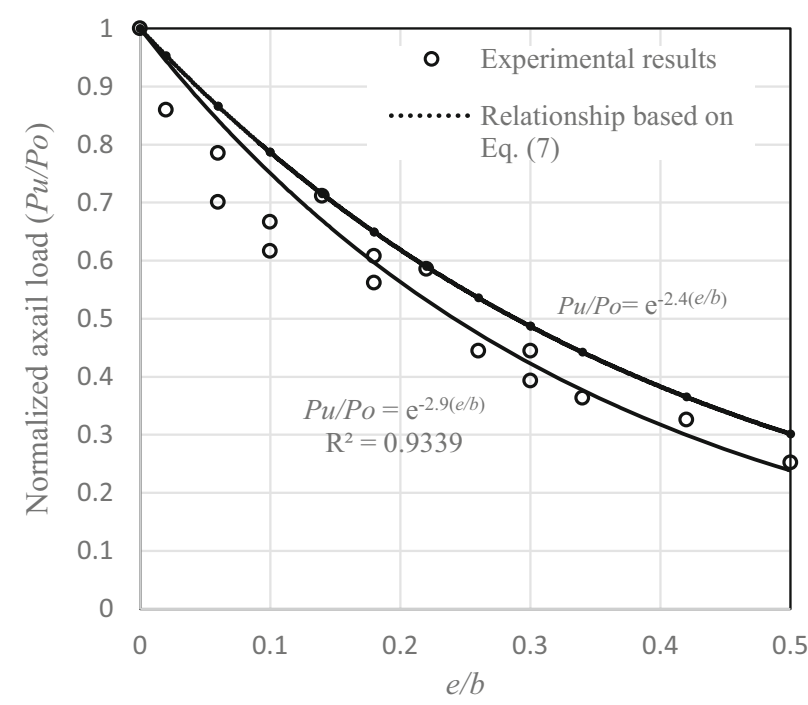

Fig. 11 Relationship between the normalized axial capacity and the end eccentricity ratio to the column side.

$H^{*}=3028 \mathrm{~mm}$,

$x_{1}=0.592 \mathrm{~m}$

$e_{o}=0.00000568 H^{* 2}=52.1 \mathrm{~mm}$

\subsubsection{Implementation of the Equivalent Column} Concept on Column Bend in Double Curvature Mode

Consider column D-3-5 as an example for column bent in double curvature mode, the equivalent pin-ended axially loaded column is determined in the following, refer to Fig. 12b.

$$
\begin{aligned}
& e_{2}=50 \mathrm{~mm}, e_{1}=30 \mathrm{~mm} \\
& e_{o}=\frac{\varepsilon_{c u}+\varepsilon_{y}}{b-c} \times \frac{H^{* 2}}{\pi^{2}}=0.00000568 H^{* 2} \\
& e=e_{o} \sin \left(\frac{\pi \times x}{H^{*}}\right) \\
& e_{1}=0.00000568 H^{* 2} \sin \left(\frac{\pi x_{1}}{H^{*}}\right)=30 \rightarrow(1) \\
& e_{2}=0.00000568 H^{* 2} \sin \left(\frac{\pi x_{2}}{H^{*}}\right)=50 \rightarrow(2) \\
& x_{1}+x_{2}=1200 \rightarrow(3)
\end{aligned}
$$

Assuming the maximum moment occurs at the end column having $50 \mathrm{~mm}$ end eccentricity and solving the three equations by trial and error yields $H^{*}=1702 \mathrm{~mm}, x_{1}=0.349 \mathrm{~m}$, $x_{2}=0.851 \mathrm{~m}$. 


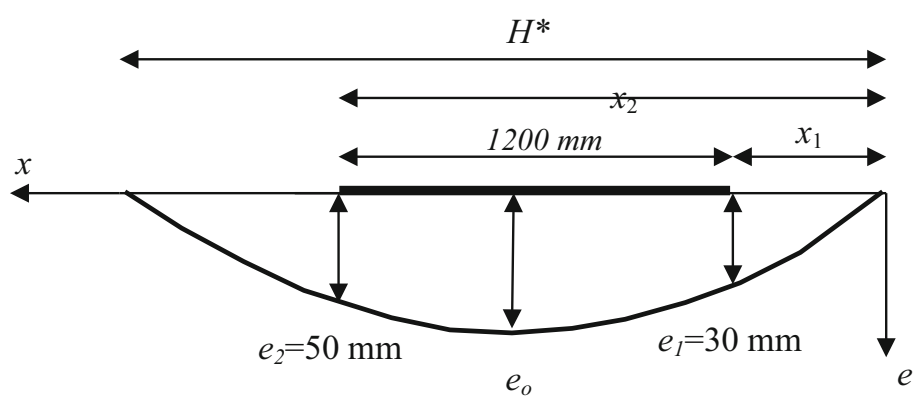

(a) Column S-3-5

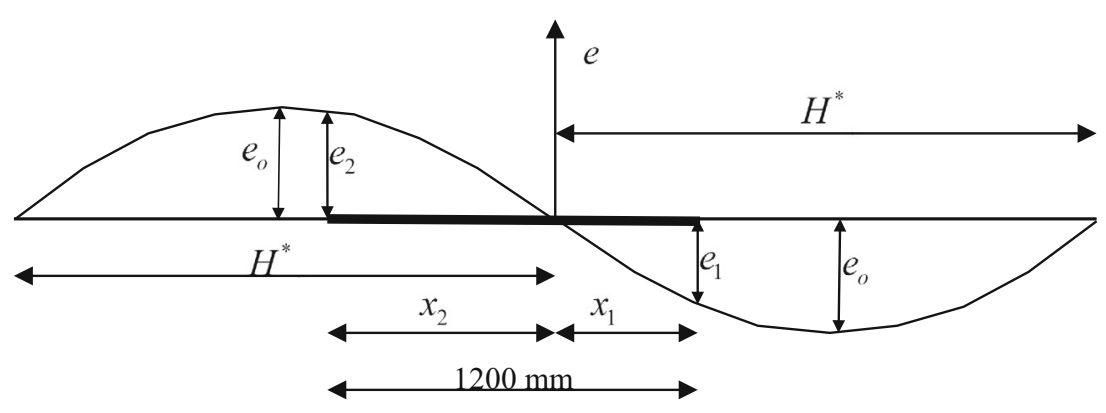

(b) Column D-3-5

Fig. 12 Representation of the equivalent axially loaded column.

It can be noted that the equivalent column for the case of double curvature mode is lower than that of the single curvature mode. Hence, the slenderness effect of the single curvature mode is higher $\left(H^{*} / b=30.28\right)$, which resulted in a significant decrease in the ultimate capacity as confirmed by the experimental result of such column (S-3-5) where its ultimate capacity was about $33 \%$ of the axial capacity of C-0-0. On the other hand, column bent in double curvature mode has slenderness ratio of 17.02 , which resulted in moderate effect on the ultimate capacity. This contact was confirmed by the experimental result where column D-3-5 showed about $56 \%$ of the ultimate capacity of axially loaded column C-0-0.

\subsubsection{Relationship Between the End Eccentricity Ratio and the Equivalent Column Length}

The same procedure used in clause 3.5.1 was implemented considering different end eccentricities combinations and the corresponding equivalent columns were obtained. Hence, a relationship between the normalized equivalent column length and the end eccentricity ratio was obtained as presented on Fig. 13 and given by Eq. (10).

$$
\frac{H^{*}}{H}=1+5(e / b)-3.17(e / b)^{2}
$$

As a consequence, knowing any end eccentricity combinations and the original column height for the column bent in single curvature mode, the equivalent pin-ended column subjected to axial load can be obtained using Eq. (10). Therefore, the design procedure could be simplified.

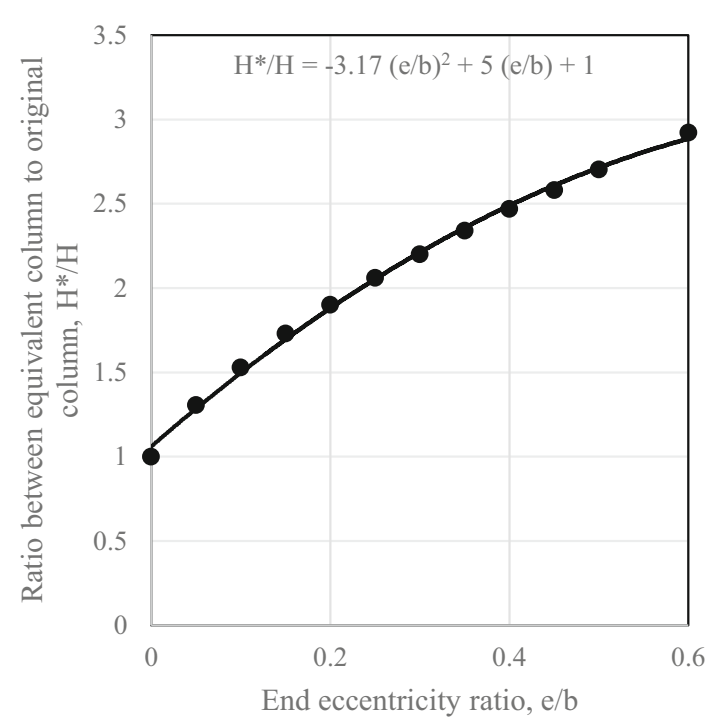

Fig. 13 Relationship between the end eccentricity ratio and the equivalent column length.

For the case of columns bent in double curvature mode, generalize the equivalent column concept maybe led to inaccurate situation and each case should be treated individually. For instance, for column having $e_{1}=5 \mathrm{~mm}$ and $e_{2}=20 \mathrm{~mm}$, the equivalent column will be 1.58 times the original column length. On the other hand, for column having $e_{1}=30 \mathrm{~mm}$ and $e_{2}=50 \mathrm{~mm}$, the equivalent column will be 1.42 times the original column length. Therefore, the value of the higher end eccentricity and the ratio between higher end eccentricity and the lower end eccentricity have to be considered. 


\subsection{Simplified Design Procedure}

The measured lateral deformation showed that inspite the column was consider as short column it exhibited lateral deformation. This lateral deformation results in decreased axial capacity of the column due to the resulting bending moment. In addition, the resulting lateral deformation is directly proportional to the column height even if the column still short one where this lateral deformation is neglected. In order to account for such additional moment as well as the acting primary end moments, the column is reduced to an equivalent pin-ended slender column. Hence, the additional moment can be calculated and the column cross-section can be proportionated using any available design charts as explained in the following.

Consider any short column subjected to any end eccentricities combinations, the column can be design as follows:

1. Calculate the equivalent end eccentricity, Eq. (6)

2. Calculate the equivalent pin-ended column, Eq. (10)

3. Check the upper slenderness limit through comparing the acting axial load and the critical buckling load, $P_{\text {critical }}$, as calculated from Eq. (11)

$P_{\text {critical }}=\frac{\pi^{2} E I}{H^{* 2}}$

where $E I$ is the flexural rigidity, which can be calculated according to the relevant design standard.

4. If the acting load is more than the critical buckling load then the column is unsafe and the concrete dimensions of the cross-section have to be increased.

5. If the acting load is less than the critical buckling load then calculate the mid-span lateral deformation $e_{o}$ from Eq. (9).

6. Calculate the additional moment as the multiplication of the acting load and the mid-span lateral deformation.

7. Use any ready-made design charts to obtain the steel reinforcement.

\subsubsection{Implementation of the Proposed Procedure}

Considered a fixed-ended braced column subjected to an axial ultimate load of $1600 \mathrm{kN}$ and the acting end moments about the minor axis are $133 \mathrm{kN}-\mathrm{m}$ and $95 \mathrm{kN}-\mathrm{m}$. The column height is $5 \mathrm{~m}$ and it has cross section 300 by $500 \mathrm{~mm}$. Assuming the flexural rigidity of the column cross section as calculated by the ACI $318-14$ as $1.04 \times 10^{13} \mathrm{~N} / \mathrm{mm}^{2}$. The design moment will be calculated by both ACI standard and the proposed procedure herein below.

\subsubsection{Proposed Procedure}

- $e_{2}=\frac{M_{2}}{P_{u}}=\frac{133}{1600}=0.083 \mathrm{~m}, e_{1}=\frac{M_{1}}{P_{u}}=\frac{95}{1600}=0.059 \mathrm{~m}$

- Using Eq. (6) the equivalent eccentricity, $e_{e q}$, equals $0.0737 \mathrm{~m}, \frac{\boldsymbol{e}_{e q}}{\boldsymbol{b}}=\frac{0.0737}{0.3}=0.245$

- Using Eq. (10), $H^{*}=H\left(1+5\left(e_{e q} / b\right)-3.17\left(e_{e q} / b\right)^{2}\right)$ $=7.24 \mathrm{~m}$

- $P_{\text {critical }}=\frac{\pi^{2} E I}{H^{* 2}}=\frac{\pi^{2} * 1.04 * 10^{13}}{7240^{2}}=3343 \mathrm{kN}>P_{u} \rightarrow O K$

- $e_{o}=\frac{\varepsilon_{c u}+\varepsilon_{y}}{b-c} \times \frac{H^{* 2}}{\pi^{2}}=\left(\frac{0.003+0.002}{270}\right) \times \frac{7240^{2}}{\pi^{2}}=98.4 \mathrm{~mm}>e_{2}$
- $M_{\text {design }}=P_{u} * e_{o}=1600 * 98.4 / 1000=157.4 \mathrm{kN}-\mathrm{m}$ $>M_{2}$

\subsubsection{ACl-318-14 Code}

- $M_{c}=\frac{C_{m} * M_{2}}{1-\frac{P_{f}}{\partial_{m} P_{c}}} \geq M_{2}$

- $\emptyset_{m}=0.75$

- $\quad P_{\text {critical }}=\frac{\pi^{2} E I}{(k l)^{2}}$

- Consider $k l=0.7$, since the column is fixed-ended at both ends, $P_{\text {critical }}=8411.4 \mathrm{kN}>P_{u} \rightarrow O K$

- $C_{m}=0.6+0.4 \frac{M_{1}}{M_{2}}=0.886$

- $\quad M_{c}=\frac{C_{m} * M_{2}}{1-\frac{P_{f}}{\emptyset_{m} P_{c}}}=\frac{0.886 * 133}{1-\frac{16000}{0.75 * 8411.4}}=157.8 \mathrm{kN}-\mathrm{m}>M_{2}$

It can noted that both methods give approximately the same design moment value; 157.4 and $157.8 \mathrm{kN}-\mathrm{m}$. That means the proposed simplified design procedure based on the equivalent column concept gives a comparable result against the results of the ACI 318-14.

\section{Conclusions}

Based on the studied end eccentricities combinations for reinforced concrete columns bent in either single or double curvature mode and according to the used concrete dimensions and adopted material properties, the following conclusions maybe drawn:

1. Providing end eccentricities resulted in decrease the axial capacity proportionally with respect to the value of the end eccentricity. For equal end eccentricities ratio of $0.5 b$, the column had lost about $75 \%$ of its axial capacity. In addition, columns bent in double curvature modes can sustain higher load than those bent in single curvature modes having the same end eccentricities combinations.

2. Considering the second order effect, the deformed shapes of columns bent in double curvature mode were approximately symmetric about the deformed shape of axially loaded column not about the original undeformed axis of the column.

3. The proposed expression correlating the axial capacity and the end eccentricity ratio showed good results against the experimental data and showed more conservative results when compared with the available formula.

4. The equivalent column concept can be generalized to simplify columns bent in single curvature modes with different end eccentricities combinations to pin-ended axially loaded columns. On the other hand, the equivalent column concept can be implemented for a particular case of a column bent in double curvature mode.

5. The results of the proposed design procedure was comparable for those obtained by the ACI 318-14 for braced columns. Therefore, as a first step, the proposed design procedure could be applied for braced columns 
and an additional work could be done to cover unbraced columns.

\section{Acknowledgments}

The experimental work had been conducted at Alexandria University's Reinforced Concrete laboratory.

\section{Open Access}

This article is distributed under the terms of the Creative Commons Attribution 4.0 International License (http://creativecommons.org/licenses/by/4.0/), which permits unrestricted use, distribution, and reproduction in any medium, provided you give appropriate credit to the original author(s) and the source, provide a link to the Creative Commons license, and indicate if changes were made.

\section{References}

Afefy H. M. (2007) Experimental and numerical instability analysis of high strength reinforced concrete systems. Ph.D. thesis, Faculty of Engineering, Tanta University, Tanta, Egypt, 244 pp.

Afefy, H. M. (2012). Ultimate flexural rigidity for stability analysis of RC beam column members. Structural and Building, 165, 299-308.

Afefy, H. M., Taher, S. F., \& El-Metwally, S. E. (2009). A new design procedure for braced reinforced high strength concrete columns under uniaxial and biaxial compression. Arabian Journal for Science and Engineering, KFUPM, KSA, 34, 349-377.

American Concrete Institute. (2014). ACI, Building Code Requirements for Structural Concrete (ACI 318-14) and Commentary. Farmington Hills, MI: ACI.

Barrera, A. C., Bonet, J. L., Romero, M. L., \& Miguel, P. F. (2011). Experimental tests of slender reinforced concrete columns under combined axial load and lateral force. Engineering Structures, 33, 3676-3689.

CAN/CSA-A23.3-04 (R2010) (2010) Design of concrete structures. Canadian Standard Association, Toronto, Ontario, Canada, 258 p.
Chen W. F., Lui E. M. (1987). Structural stability: Theory and implementation, New York, NY: Elsevier Science Publishing Co., Inc., 483 pp.

Chuang H., Kong F. K. (1997) Large scale tests on slender reinforced concrete columns. Journal of the Institution of the Structural Engineers, Nanyang Technological University, Singapore, 75, 410-416.

Cranston W. B. (1972) Analysis and design of reinforced concrete columns. Cement and Concrete Association, No. 20, $54 \mathrm{p}$.

Egyptian Code for Design and Construction of Reinforced Concrete Structures, (ECP 203-2007) 2007.

El-Metwally, S. E. (1994). Method of segment length for instability analysis of reinforced concrete beam-columns. ACI Structural Journal, 91, 666-677.

Ivanov, A. (2004). Special features for the design of slender columns in monolithic multistory buildings with the consideration of longitudinal bending. Journal of Concrete and Reinforced Concrete, 5, 27-29.

MacGregor, J. G., Breen, J. E., \& Pfrang, E. O. (1970). Design of slender columns. ACI Structural Journal, 67, 6-28.

MacGregor, J. K., \& Wight, J. G. (2009). Reinforced concrete: Mechanics and design (5th ed.). Upper Saddle River, NJ: Prentice Hall.

Mari, R., \& Hellesland, J. (2005). Lower slenderness limits for rectangular concrete columns. Journal of Structural Engineering, ASCE, 131, 85-95.

McCormac, J. C. (1998). Design of reinforced concrete (4th ed.). Menlo Park, CA: Addison-Wesley Longman, Inc.

Milner, D. M., Spacone, E., \& Frangopol, D. M. (2001). New light on performance of short and slender reinforced concrete columns under random loads. Engineering Structures, 23, 147-157.

Mirza, S. A., \& MacGregor, J. G. (1982). Probabilistic study of strength of reinforced concrete members. Canadian Journal of Civil Engineering, 9, 431-448.

Nilson, A. H. (2004). Design of concrete structures (10th ed.). New York, NY: McGw-Hill book Company.

Park, H., \& Paulay, T. (1975). Reinforced concrete structures. New York, NY: Wiley.

Yalcin, C., \& Saatcioglu, M. (2000). Inelastic analysis of reinforced concrete columns. Computers \& Structures, 77, $539-555$. 